\title{
Damage Assessment of Offshore Riser-guards under Accidental Vessel Impact
}

\author{
Zubair Imam Syed, Osama Ahmed Mohamed \\ Department of Civil Engineering, Abu Dhabi University, \\ Abu Dhabi, P.O. Box 59911, United Arab Emirates
}

\author{
Dinesh Palaniandy, Mohd Shahir Liew \\ Offshore Engineering Centre, Universiti Teknologi \\ PETRONAS, Tronoh, 31750 Malaysia
}

\begin{abstract}
Steel riser-guards are installed on offshore jacket platforms to provide protection to risers against vessel collision. As risers transport the crude oil which is highly flammable, a collision between vessel and risers has the potential of causing severe structural damage to the platform and injuries to on-board service personnel. Due to lack of indepth investigation on the response and damage of conventional riser-guards under an accidental vessel collision, the current practice of design of steel riser-guards is open to further improvement in terms of level of protection and economy. This paper presents a new approach in assessing the level of damage on conventional steel riser-guards, in the event of a collision with offshore supply vessels. Systematic numerical investigations were performed using non-linear finite element analysis to explore the structural response and damage under accidental vessel impact. This investigation was aimed to assess the adequacy of the protection provided by the conventional riser-guard and to ascertain the damage level under its maximum capacity in energy dissipation. The results from this investigation show that the conventional riser-guard does not only provide sufficient protection under accidental vessel impacts, but also indicates toward an overly-designed protection system which possesses much higher capacity than the design requirements for offshore oil producing regions in South China Sea.
\end{abstract}

Keywords- steel riser-guard, accidental vessel impact, damage assessment.

\section{INTRODUCTION}

Risers in jacket platforms transport highly flammable crude oil and natural gas extracted from the reservoir to the processing facilities. Risers are often clamped to the jacket legs, or to brace members for support and stability. The location and the nature of risers make them a soft target under accidental lateral impact from supply vessels. Several past remarkable incidents and resulting devastations had prompted the use of riser-guards to prevent incidents similar to the Mumbai High North platform explosion [1]. Supply vessels used for providing services to the offshore platforms come in a variety of sizes, typically measured in terms of displacement tonnes, ranging from 1000 to 2500 displacement tonnes depending on the region of operation. Aas et.al [2] highlighted on the absence of a properly established ship routing and scheduling to systematically manage the operation of vessels in the vicinity of oil platforms, which exposes the realistic probability of an accidental collision between the vessels and the risers. The risk of a collision involving vessels and platforms is closely related to the density of traffic at the vicinity of platforms. In a special research report published by the Health and Safety Department of U.K [3], a total number of 353 incidents involving supply vessels and platforms at the U.K Continental Shelf (UKCS) were reported between the years of 1975 to 2001. Over the years, numerous protection systems have been employed for riser, and the use of conventional steel frame attached to the jacket legs are the most common and widely used. There is a gap indepth investigation on the response and damage of conventional riser-guards under an accidental vessel collision, the current practice of design of steel riserguards is also open to further improvement in terms of level of protection and economy.

This paper presents a new approach in assessing the level of damage on conventional steel riser-guards, in the event of a collision with offshore supply vessels using systematic numerical investigations which can improve the understanding of structural response and damage under accidental vessel impact.

\section{COMMON DAMAge Assessment APPROACHES}

In the oil and gas industry, commonly used qualitative structural assessments are carried out periodically on all assets, which are largely based on visual inspection. For the case of steel tubular members under impact, the maximum energy due to impact which a steel tubular member could sustain is limited by the local buckling on the compression side, or fracture along the tensile side of the member. The ductility limit recommended by ISO 19902 states that a steel tubular member can be conservatively assumed to have disconnected when the extreme fibre experiences strain values higher than 5\% [4]. However, in determining the actual capacity of a structure, conservatism should be applied minimally to be able to accurately assess the structural capacity against impact. The various methods of performing damage assessment and a comparison study on damage indexes for steel moment frames was performed by Estekanchi and Arjomandi [5].

In this present study however, plasticity based damage assessment was performed on conventional steel riserguard by evaluating the percentage of damaged and undamaged elements during accidental vessel impact. The American Petroleum Institute (API) Recommended Practice for Planning, Designing, and Construction of Fixed Offshore Platforms [6] classifies the steel tubular members used for offshore structures in to three groups 
and among them Group 1 which consists of mild steel with minimum yield strength of $240 \mathrm{MPa}$ is commonly used for offshore riser-guards. Primary members which are made of high strength steel are designed to operate within its elastic limit. Any form of permanent deformation such as denting, would be considered to be unacceptable as it may lead to a chain of events, causing major structural failures.

\section{THE LOWER SOLUTION BASED ON INTERPOLATION}

Conventional steel riser-guards were modelled using general purpose finite element analysis software package, ANSYS Mechanical. Transient non-linear analysis was performed by applying triangular impulse loads, equivalent to vessel collision on the conventional riserguard and the resulting structural response are used to perform damage assessment. The method used to establish the collision forces equivalent to vessel impact has been previously highlighted in a separate publication by the authors [7]. A similar approach was also used by Jin et al. [8] in assessing damage due to barge impact on brace members of jacket platform. The riser-guards modelled in this study had a width of 14 meters and height of 10 meters. The riser-guard material was mild steel with yield strength of $240 \mathrm{MPa}$, ultimate strength of $430 \mathrm{MPa}$ whereas yield and ultimate strains used were 0.0012 and 0.2 respectively.

Bilinear kinematic plasticity model was utilized to take into account the structural behaviour beyond the elastic limit. Two scenarios were simulated in this study, which are the broadside impact and bow impact at the mid-span of the riser-guard. Impulse forces for both broadside and bow collision was idealised to be acting uniformly across the highlighted members, which are highly likely to come into contact during collision. The probable locations of contact between vessel and riserguard were established based on the typical configuration of supply vessel with bulbous bow, as shown in Fig. 1. Fig. 2 shows the CAD model of the conventional steel riser-guard, with the location of impact highlighted in red.

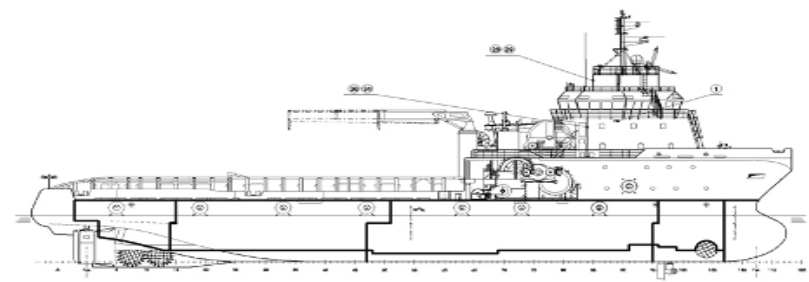

Figure.1. Typical supply vessel configuration [9]
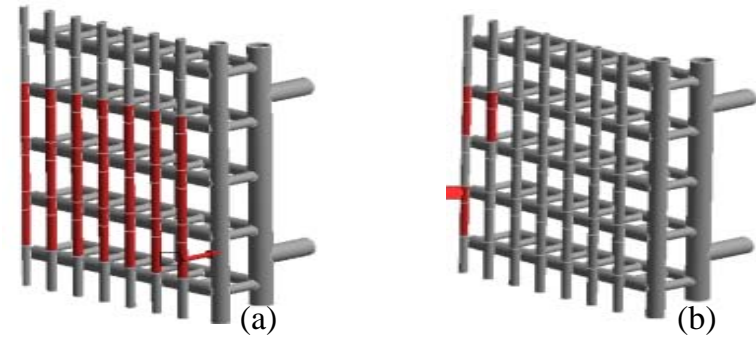

Fig. 2. Location of vessel impact; (a) broadside impact and (b) bow impact

Fig. 3 shows the maximum deformation of riser-guard for both broadside impact and bow impact. The broadside impact results in global structural deformation, indicating that the impact energy dissipation was achieved by global structural displacement. Impact energy dissipation for the case of bow impact however, differs from the broadside impact, where local denting was predominant in impact energy dissipation.

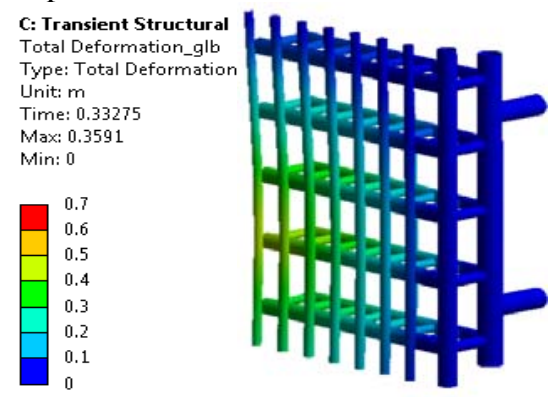

(a)

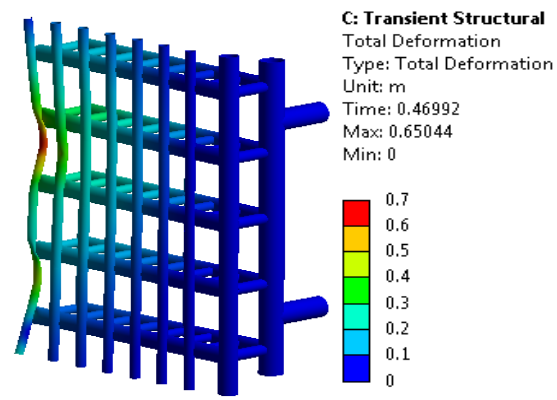

(b)

Fig.3. Maximum deformation of riser-guard for: (a) broadside vessel impact and (b) bow vessel impact

\section{DAMAgE Assessment}

In the finite element simulation, two approaches are used to identify damage. Total strain at critical joints which has the potential to clearly indicate the damage states of the riser-guard members were used along with the distribution of damaged and undamaged elements to map the damage level of riser-guards.

\section{A. Total Strain at Critical Joints.}

Prior to performing the analysis, critical joints were first identified and the strain levels at these locations were extracted. A failure strain of $0.2 \mathrm{~m} / \mathrm{m}$ was selected to 
describe the ultimate strain limit before fracture. Fig. 4 shows the total strain distribution along primary members for broadside and vessel bow impact. The locations of critical joints were highlighted with red circles in Fig.4 (a). Failure of these critical joint would result in significant reduction in the lateral stiffness of the structure, and therefore it was assumed that when the failure strain limit at critical joints were exceeded, the global structure of riser-guard could be considered to have undergone overall structural failure. Strain distribution Fig.4 (a) indicates that during vessel collision, the damage primarily occurs at the critical joints, where the strain values are much closer to the failure limit. However, Fig.4 (b) shows that the damage from vessel bow impact is concentrated only at the location of contact, where maximum strain occurs at mid-span of riser-guard.

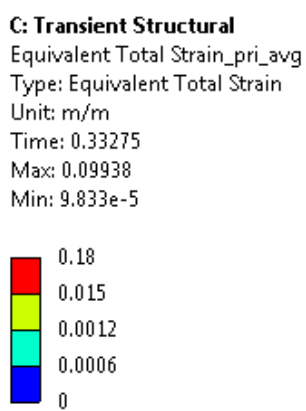

(a)

C: Transient Structural
Equivalent Total Strain_pri_avg
Type: Equivalent Total Strain
Unit: $\mathrm{m} / \mathrm{m}$
Time: 0.47342
Max: 0.10099
Min: $6.0476 \mathrm{e}-5$
$\begin{aligned} & 0.18 \\ & 0.015 \\ & 0.0012 \\ & 0.0006 \\ & 0\end{aligned}$

(b)

Fig.4. Maximum strain distribution along primary members for (a) broadside vessel impact, (b) vessel bow impact.
The critical joints show strain values much lower than the failure limit, suggesting that in the event of a vessel bow impact, the riser-guard is likely to experience local damage while the global structure remains relatively intact, unlike impact from broadside of a vessel. Fig. 5 and Fig. 6 show the time-history of the total strain development at the critical joints.

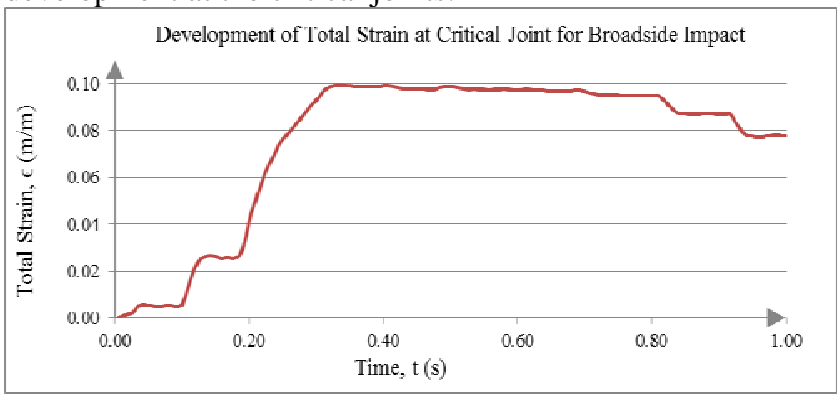

Fig.5. Total strain at critical joint resulting from broadside vessel impact

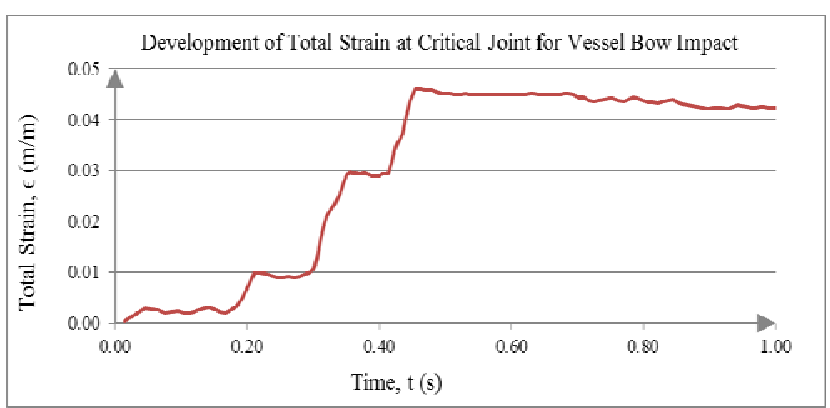

Fig.6. Total strain at critical joint resulting from vessel bow impact

\section{B. Total Strain at Critical Joints.}

An element which exceeds the elastic limit of $0.12 \%$ is considered to have experienced damage, whereby the element remains permanently deformed. The distribution of both undamaged and damaged elements for both broadside impact and bow impact is presented in Fig. 7 . This figure shows that for the case of broadside vessel impact, elements remaining within the elastic limit are less than $40 \%$. However, most of the damaged element remains within the range of $0.0012 \mathrm{~m} / \mathrm{m}$ to $0.005 \mathrm{~m} / \mathrm{m}$, which barely exceeds the elastic limit and remains relatively far from the failure limit. This suggests the presence of additional capacity for higher impact energy dissipation, provided that the critical joints remain intact. 


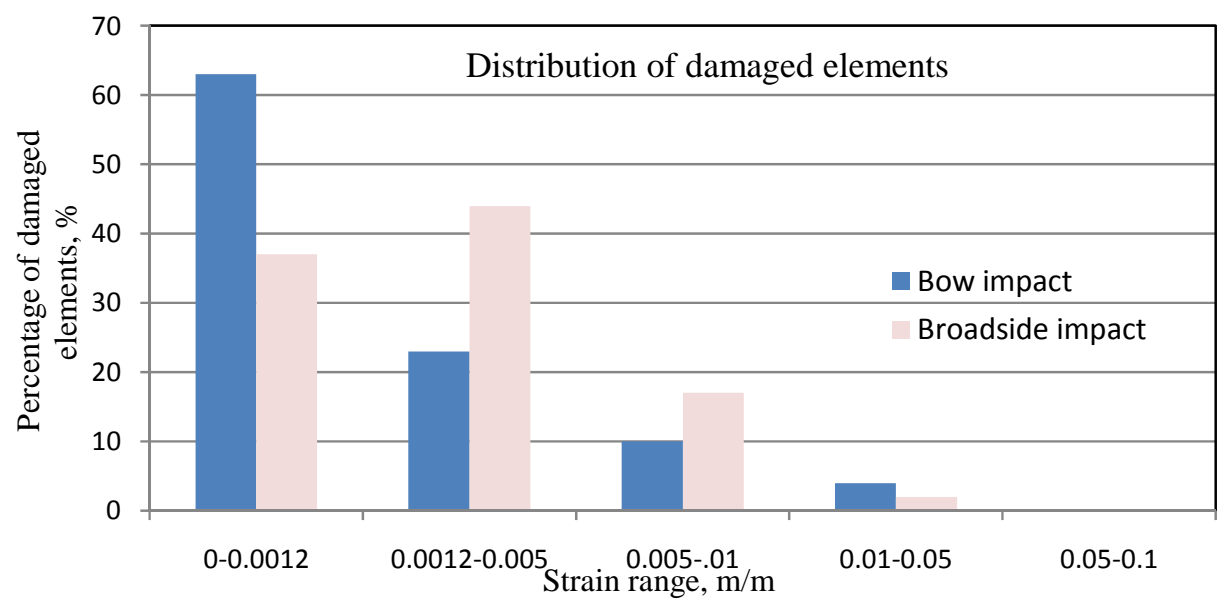

Fig.7. Distribution of damaged and undamaged elements along primary members for vessel broadside impact

From Fig. 7 it can also be observed that more than $60 \%$ of the elements remain undamaged as a result of vessel bow impact. This also indicates to the damage being concentrated at the location of contact between vessel and riser-guard while elements away from the local damage remain relatively undamaged.

\section{CONCLUSIONS}

The conventional riser-guards are designed to sustain impact energy of up to $2.25 \mathrm{MJ}$, from accidental vessel collision. Two possible scenarios were investigated in this study, and the following conclusion can be drawn:

1 . The protection provided by conventional riser-guard for 2.25 MJ of impact energy is sufficient.

2. The conventional riser-guard possesses higher capacity of impact energy dissipation than the requirement for some regional operations like that of South China Sea.

3. Protection against vessel broadside impact is much more critical as it results in global structural damage. Critical joints under broadside impact were much closer to failure as compared to those from vessel bow impact.

4. The maximum deformation corresponding to 2.25 $\mathrm{MJ}$ is lesser than the available clearance between riserguard and risers on a typical jacket platform.

\section{ACKNOWLEDGEMENTS}

The first author would like to show his appreciation to the Offshore Engineering Centre of Universiti Teknologi PETRONAS (UTP) for providing resources and some technical data for this research.

\section{REFERENCES}

[1] Mitra, N. K., Dileep P. K., Kumar A. Revival of Mumbai High North - A Case Study. Proceedings of SPE Indian Oil and Gas Technical Conference and Exhibition, Mumbai, 2008.
[2] Aas, B., Halskau, Wallace, S. W. On the role of supply vessels in offshore logistics, Journal of Maritime Economics and Logistics,11, pp. 302-325, 2009.

[3] Robson, J. K. Ship/platform Collision Incident Database. HSE Books, Norwich, 2003.

[4] International Standard-ISO:19902. Petroleum and Natural Gas Industries- Fixed Offshore Steel Structures. ISO, Switzerland, 2007.

[5] Estekanchi, H., Arjomandi, K., On the Comparison of Damage Indexes in Nonlinear Time History Analysis of Steel Moment Frames, Asian Journal of Civil Engineering (Building and Houses), 8(6), pp. 629-646, 2007.

[6] American Petroleum Institute. Recommended Practice for Planning, Designing and Constructing Fixed Offshore Platforms - Working Stress Design. API, Washington, 2007.

[7] Palaniandy, D. K., Liew, M. S., Karuppanan S., Syed, Z. I. Estimation of Vessel Stopping Time During Collision with Offshore Riser-Guard. Proceedings of FTSCEM, Bangkok, pp. 116-120, 2013.

[8] Jin, W., Song, J., Gong, S., Lu, Y. On the Evaluation of Damage 0n Offshore Platform Structures due to Collision of Large Barge, Journal of Engineering Structures, 27, pp. 1317-1326, 2005.

[9] Hartman Offshore, “Anchor Handling Tug Supply Vessel,” HO, $2008 . \quad$ [Online].Available:http://www.hartmannoffshore.com/fleet.php?l=en. Accessed 15 April 2014]. 